\title{
Editorial
}

\section{Economics of Bioenergy}

\author{
Amani Elobeid, ${ }^{1}$ Miguel Carriquiry, ${ }^{2}$ Silvia Secchi, ${ }^{3}$ and Tun-Hsiang (Edward) $\mathbf{Y u}^{4}$ \\ ${ }^{1}$ Center for Agricultural and Rural Development, Iowa State University, Ames, IA 50011-1070, USA \\ ${ }^{2}$ Facultad de Agronomía, Univeridad de la República, Avenue Eugenio Garzón 780, Montevideo 12900, Uruguay \\ ${ }^{3}$ Department of Agribusiness Economics, Southern Illinois University, Carbondale, IL 62901-4619, USA \\ ${ }^{4}$ Department of Agricultural and Resource Economics, The University of Tennessee, Knoxville, TN 37996-4518, USA
}

Correspondence should be addressed to Amani Elobeid; amani@iastate.edu

Received 7 November 2013; Accepted 7 November 2013

Copyright (C) 2013 Amani Elobeid et al. This is an open access article distributed under the Creative Commons Attribution License, which permits unrestricted use, distribution, and reproduction in any medium, provided the original work is properly cited.

There has been worldwide support for the production and use of renewable energy sources, especially through major policy initiatives relating to climate change and bioenergy. These policies include the United States' Environmental Protection Agency's Renewable Fuel Standard (RFS2) and the American Clean Energy and Security Act (ACES) of 2009 (H.R. 2454), Brazil's 2009 National Climate Change Policy, Canada's 2006 Renewable Fuels Regulations, and the European Union's 2009 Energy and Climate Change Package. The rationales behind these policies have been multifold, ranging from less reliance on imported fuels, reducing energy prices, and improving the rural economy to mitigating climate change. Some have argued that bioenergy has not delivered on its promise of energy security and reduction in greenhouse gas emissions, especially in the case of field crops utilized to produce biofuels, bioheat, and biopower. The economic and environmental consequences of this bioenergy expansion have not been fully understood, primarily because bioenergy markets are not well developed and are still in flux. The main objective of this special issue is to better understand the emergence of bioenergy markets and explore the direct or indirect consequences of the expansion of this alternative energy source on the economy, energy, and commodity markets and associated environmental impacts at the country, regional, or global level. The broad range of environmental and economic impacts of biofuel production as well as their dependence on specific feedstocks and landscapes is reflected in the articles of this special issue.

Y. W. Zhang and B. A. McCarl analyze the effects of autonomous adaptation-adjusted climate change and the
Renewable Fuel Standard (RFS2) on US agriculture. For this analysis, the authors use the agricultural component of the FASOMGHG model, which models land use allocation within the US agricultural sector. The results show that while the impacts of climate change and RFS2 act in opposite directions, there is a net positive effect on agricultural consumer welfare and agricultural producer income. The results also suggest that, for RFS2 biofuel production, climate change promotes the use of crop residues and energy crops (other than switchgrass) for cellulosic ethanol production.

F. Taheripour and W. E. Tyner use a multiregional computable general equilibrium model (GTAP-BIO), modified to include second-generation biofuels, to evaluate induced land use change (ILUC) emissions for alternative biofuel pathways in the United States. They calculate the ILUC emissions using four existing major emission factors and examine the uncertainties related to these factors and their consequences for the estimated ILUCs. The results show that the production of biofuels from dedicated energy crops shifts existing marginal cropland-pasture to crop production and also causes moderate deforestation. The largest land use change is generated from growing switchgrass as a biofuel feedstock while the lowest land use change is generated from Miscanthus for bio-gasoline production. This result is mainly due to the assumed yields for the two crops. However, biofuel production from crop residues, such as corn stover, does not significantly affect land use. The authors observe that calculated ILUC emissions are subject to uncertainties in emission factors based on the inclusion or exclusion of cropland-pasture, changes in soil carbon sequestration due to changes in land cover vegetation, and the wide divergence 
among emission factor sources, especially for dedicated crop conversion to ethanol.

A. Elobeid et al. present the impact of two emissionsmitigating policies, a US fertilizer tax and a policy incentivizing afforestation, on both US and world agricultural markets. Both policies are aimed at mitigating the adverse environmental effects of the expanding production of agricultural crops used as feedstock for biofuels. The authors use the FAPRI-CARD agricultural modeling system, which is a set of multimarket, partial-equilibrium, and nonspatial econometric models, for this analysis. The study also evaluates the impact of these policy scenarios on global agricultural greenhouse gas (GHG) emissions using a model that accounts for GHG emissions from agriculture. Results show that a US tax on fertilizer reduces the production of nitrogen-intensive crops. However, the impact on GHG emissions is muted as the lower fertilizer use in the USA is partially offset by higher fertilizer use in the rest of the world, which expands crop production in response to higher prices. A policy that shifts cropland to forestland (afforestation) also results in an unintended increase in global GHG emissions. Crop production shifts from highyielding land in the United States to low-yielding land, and probably native vegetation in the rest of the world. Thus, the study shows that unilateral policy changes implemented by a large agricultural producer like the United States can have fairly significant impacts on the aggregate world commodity markets. This analysis highlights the importance of internationally coordinated action in order to avoid the unintended consequences of inadvertent increases in global greenhouse gas emissions.

T. A. Maung and C. R. Gustafson analyze the impact of harvest field time on the potential profit of supplying corn residues (cob or stover) by farmers for biofuel production in North Dakota. As the harvest window for crops is relatively short in the north-central United States due to the weather, the variation in available field time is likely to affect the volume of corn and the residues collected by farmers and their profits. The authors apply mathematical programming models to analyze three harvest options in this study including (i) corn grain only harvest, (ii) simultaneous corn grain and cob harvest in a one-pass operation, and (iii) separate corn grain and stover harvest in a two-pass operation. By simulating the availability of the fall harvest field times, results show that the available time to collect corn and residues is very influential to the net profit of corn producers. Also, allocating time to collect either cob or stover by farmers would result in less time for corn harvest and potentially lower net profit for the producers. Thus, the study suggests that it would be more economically efficient to have a professional entity to collect the residues.

D. Brent and S. Rabotyagov examine the land use impact of producing biofuels from forest residues in Washington State given that converting land to different uses could create diverse impacts on the environment. Applying a random utility maximization model to a spatially explicit parcel database, the decision of land use change is analyzed. Based on the estimated landowner's decision model, the potential impact of two hypothetical biofuel policies on land use change in the state is then simulated. When assuming higher forest returns due to increasing use of forest residues for biofuel production, the increases in forestland range between 0.1 and $1 \%$. In addition, the area of forestland increases by $0.1-$ $0.5 \%$ assuming the development of a conversion facility in the state. The potential expansion in the use of forestland for biofuel production implies a net reduction in atmospheric carbon, which is in contrast to the experience of corn-based ethanol.

B. C. English et al. assess the economic impact of growing switchgrass, a native perennial, for second-generation biofuel production in Eastern Tennessee linking a mathematical programming model of lignocellulosic biomass feedstock supply chain to a regional scale Input-Output model. The study adds to the literature by including a wide range of remote sensing and spatially explicit information such as crop yields, soil types, real road networks, and land ownership type into the determination of the optimal location of a secondgeneration biorefinery. The authors then estimate the effects of this optimally located biorefinery on the local economy, including the one-time investment activities associated with the establishment of a perennial grass and the construction of the biorefinery and the ongoing operation of the plant, with its associated supply chain. The study considers the sensitivity of the results to several harvest technology and storage scenarios, and the authors conclude that the biorefinery would be a net benefit to the local economy, partly because the opportunity costs of the production of switchgrass, pasture, and hay are associated with an industry in decline in the region. This study illustrates the importance of incorporating spatially explicit information in the analysis of logistics of biofuels and the value of incorporating full supply chain information for the industry. It provides the type of information that is critical to private sector investors, policy makers, and farmers.

E. Affuso and L. M. Duzy study another set of important issues associated with land-based biofuel production, namely, their impact on the environment. The authors integrate a stochastic discrete model of profit maximization incorporating climate information with a widely used water quality model to determine the environmental impact of firstgeneration ethanol and biodiesel production in northern Alabama. The authors specifically focus on the potential role of the El Niño Southern Oscillation (ENSO) cycle in the farmers' choice of crops and the impacts of these choices on nutrients losses in surface waters. Crop yields are stochastically dependent on the ENSO phase. The authors examine two biofuel levels production scenarios associated with meeting different levels of the Renewable Fuel Standard mandate and associated crop prices to assess long term expected production levels and nitrogen losses. They find that as corn production increases to meet the mandate, nitrogen losses increase, albeit less than proportionally. This is consistent with the findings of previous literature. This study links a globally important weather phenomenonthe ENSO cycle-with individual farmers land use choices given large scale policies and their impacts on environmental variables. It adds to the literature by illustrating the importance of including weather-related uncertainty 
to individual choices and their impact on the environment.

Amani Elobeid Miguel Carriquiry Silvia Secchi

Tun-Hsiang (Edward) Yu 

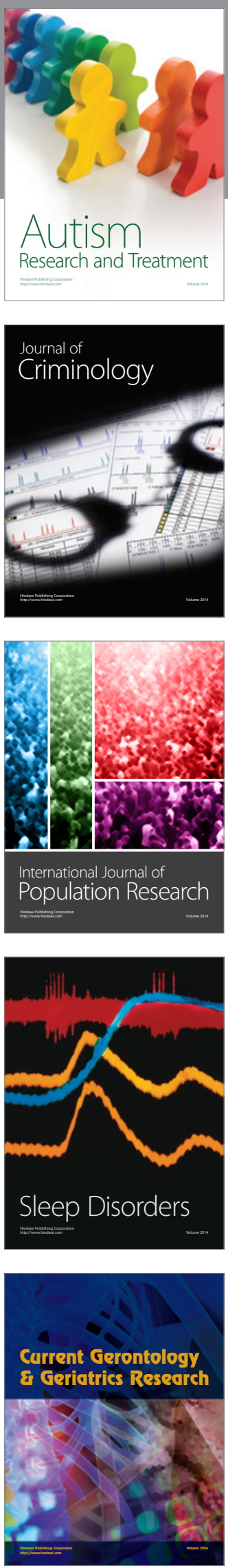
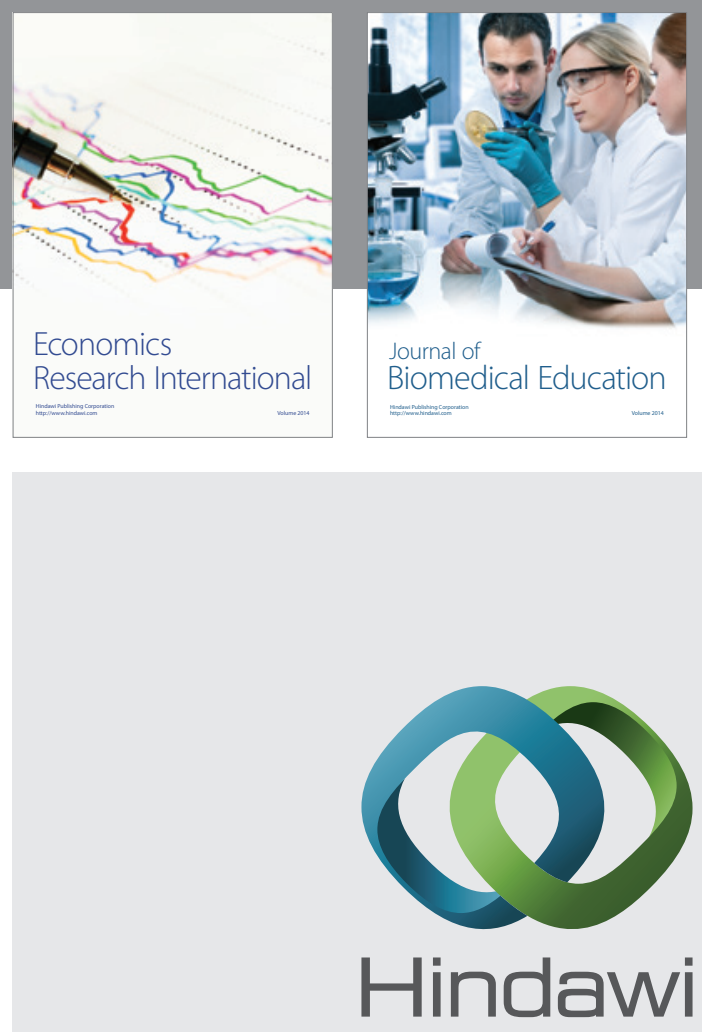

Submit your manuscripts at

http://www.hindawi.com
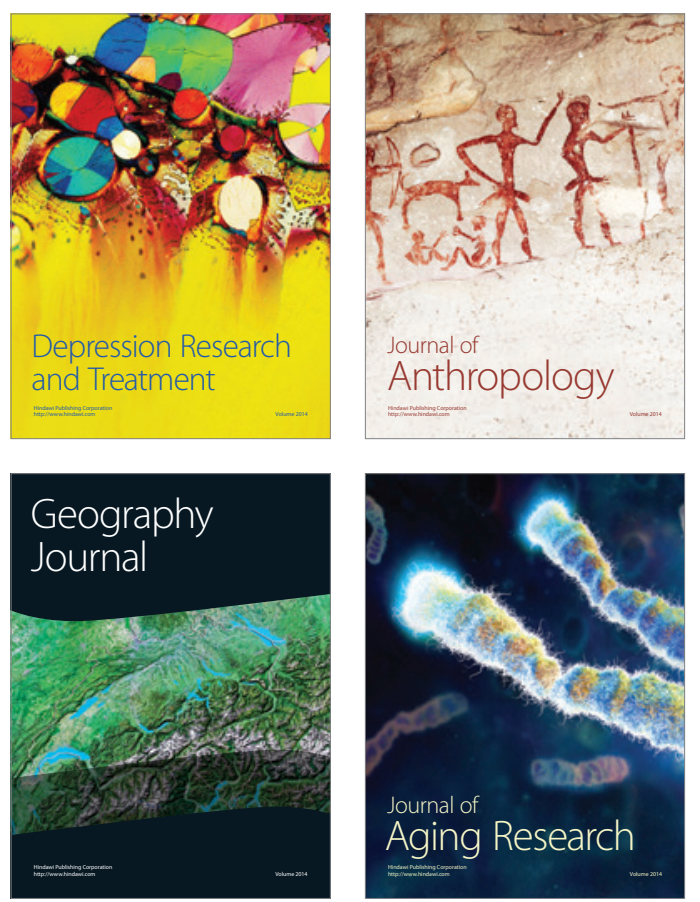
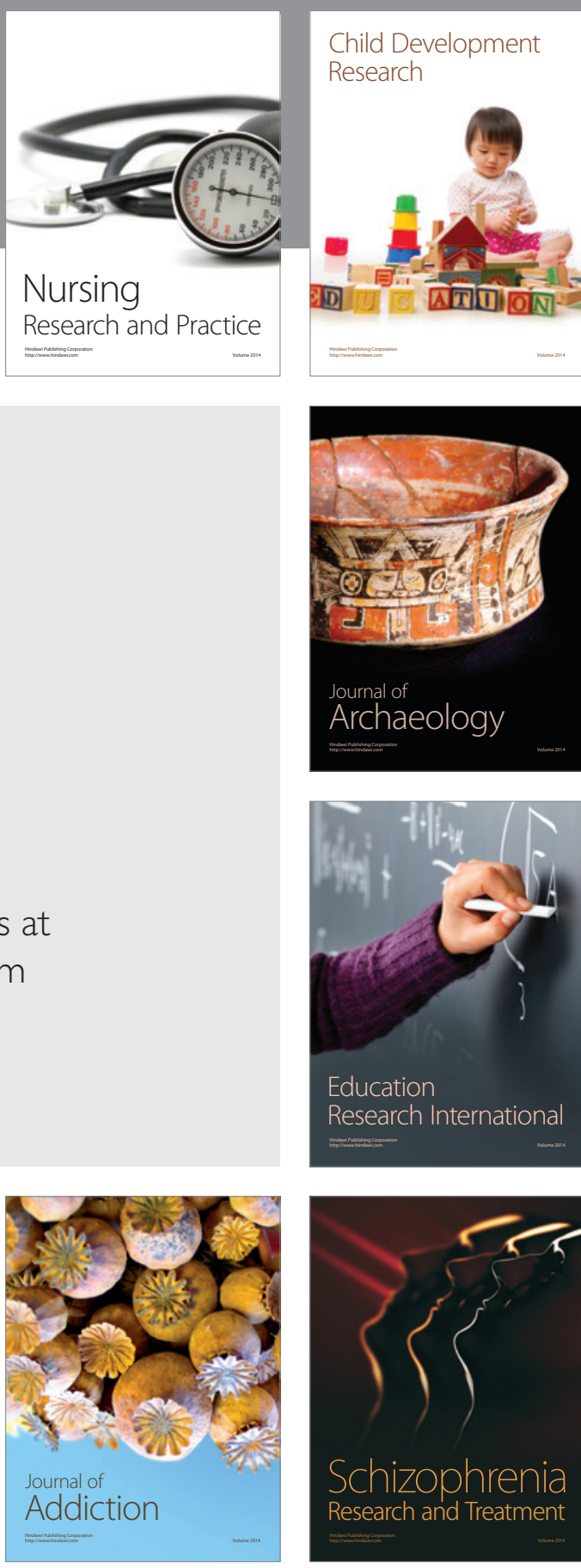

(D)
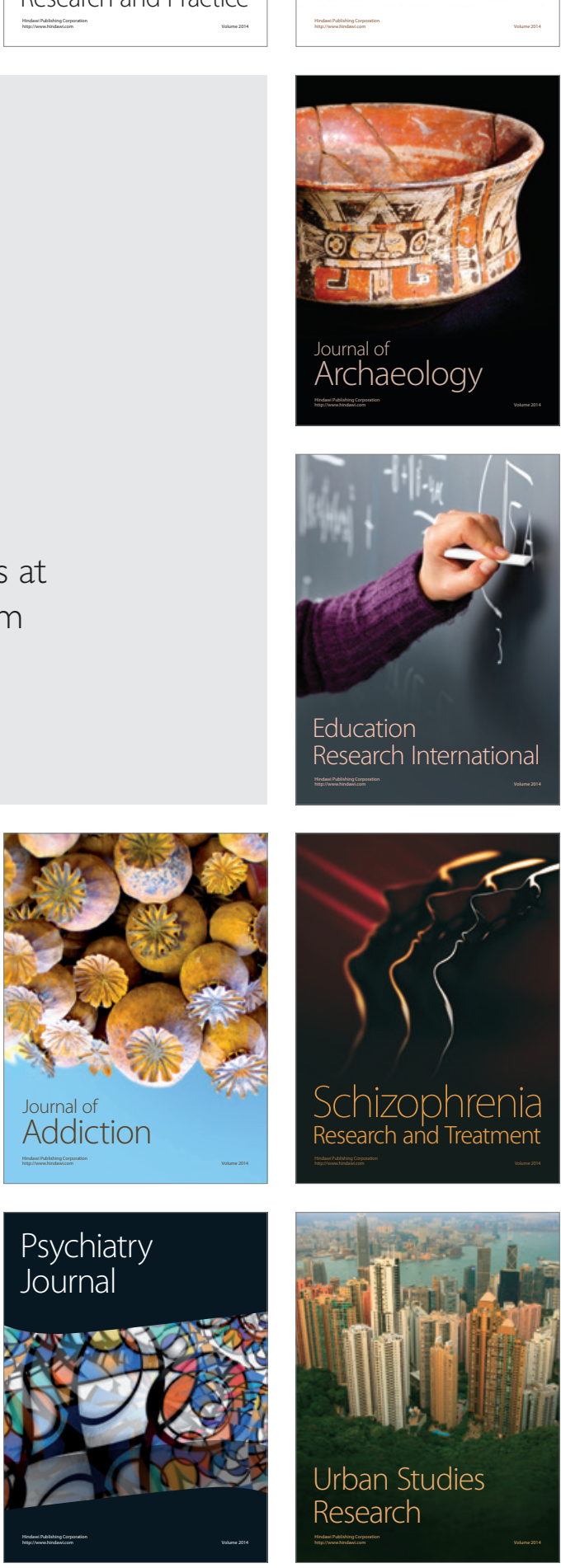